interaction between Neuroticism and Conscientiousness as "Healthy Neuroticism". Here, we aim to establish the replicability of Healthy Neuroticism in association with mortality. We conducted a coordinated integrative data analysis of 14 prospective cohorts, from 5 countries, with a combined $\mathrm{N}$ of nearly 100,000. Overall, there was weak support replicated across studies for higher levels of neuroticism being protective, in terms of mortality risk, when conscientiousness levels were also high. Ours is the first large-scale systematic effort to estimate replicability and generalizability of Healthy Neuroticism. We discuss implications for future research in the field of lifespan personality and health.

\section{INTERNAL REPLICATION STRATEGIES FOR (MODERATELY) LARGE SAMPLES: CROSS- VALIDATION TECHNIQUES IN PROJECT TALENT}

B. Chapman ${ }^{1}$, A. Huang ${ }^{2}$, E. Horner ${ }^{3}$, K. Peters ${ }^{4}$, E. Sempeles ${ }^{5}$, B. Roberts ${ }^{6}$, S. Lapham ${ }^{7}, 1$. Departments of Psychiatry and Public Health Sciences, URMC, Rochester, New York, United States, 2. American Institutes for Research, Washington, DC, USA, 3. American Institutes for Research, Washington, DC, USA, 4. American Institutes for Research, Washington, DC, USA, 5. American Institutes for Research, Washington, DC, USA, 6. University of Illinois, Champaign, IL, USA, 7. American Institutes for Research, Washington, DC, USA

Integrative analysis of several distinct studies has become the gold standard for replicability. At times however, researchers may have only one data source. When it is sufficiently large, however, single studies permit the deployment of a range of cross-validation methods that permit one to examine the consistency, stability, or replication of parameter estimates such as regression coefficients. Using an example from Project Talent, a large cohort study, k-fold, jackknife, and bootstrap cross-validation are demonstrated in a survival analysis predicting 49-year mortality from adolescent personality traits. Both simple graphical and formal measures of cross-validation consistency are then reviewed, and guidelines for quantifying and presenting the stability of results are considered. The promises and perils of internal cross-validation in smaller samples are also discussed.

\section{SESSION 2475 (SYMPOSIUM)}

\section{INTEREST GROUP SESSION - ASSISTED LIVING: LICENSED NURSE AND ADMINISTRATOR CHARACTERISTICS IN U.S. RESIDENTIAL CARE COMMUNITIES}

Chair: P.C. Carder, Portland State University, Portland, Oregon

Discussant: S. Zimmerman, School of Social Work, University of North Carolina, Chapel Hill, North Carolina

This symposium includes four papers focusing on nurse staffing and administrator characteristics in U.S. residential care communities (RCC). Unlike nursing homes, staffing types and levels in RCCs remain understudied, especially considering the importance of staffing for residents' quality of life and with health services use. Three of the papers use national data managed by the National Center for Health Statistics, and one is based on an 8-state study. Based on quantitative analysis of survey data, these papers advance existing knowledge by providing recent findings about statelevel variation in nurse staffing levels in RCCs compared to other LTC settings (Harris-Kojetin), and by identifying state variation based on regulatory requirements. For example, Rome and colleagues report that RCCs in states with licensed nurse requirements have a statistically significantly higher prevalence of both registered nurses and licensed practical/ vocational nurses. An 8-state study (Beeber \& Zimmerman) found that licensed nurse staffing and roles of non-nurse care providers and availability of specific nursing services also varies in relation to states' nurse delegation requirements and definitions of staffing practices. Finally, the paper by Dys and colleagues provides the first analysis of national data to examine characteristics associated with administrator tenure in RCCs. Collectively, these studies increase knowledge about state variation in licensed nurse staffing levels and characteristics and about RCC administrator tenure. The discussant will compare these results to what is known about nursing home staffing, and will suggest policy and research implications.

\section{VARIATION IN LICENSED NURSE PREVALENCE AND STAFFING LEVELS AMONG PAID LONG-TERM CARE SECTORS}

\section{Harris-Kojetin, National Center for Health Statistics,} Hyattsville, Maryland, United States

Previous studies find that higher nurse staffing levels are associated with better outcomes for nursing home residents; nursing homes are required to meet federal Medicare and Medicaid minimum nurse staffing ratios. Less research exists on staffing in adult day and residential care settings, which are state-regulated but not federally-regulated. This presentation presents findings from Long-Term Care Providers and Services Users in the United States: Data from the National Study of Long-Term Care Providers, 2015-2016, to be published in late 2018. We compare the estimated prevalence of and staffing levels (average hours per resident per day) for employee registered nurses (RNs) and licensed practical/ vocational nurses (LPNs/LVNs) in three sectors. The average licensed nursing hours per resident or participant per day in nursing homes ( 1 hour and 22 minutes) were more than twice the size of the corresponding ratios for residential care (22 minutes) and adult day (28 minutes).

\section{VARIATION IN LICENSED NURSE STAFFING CHARACTERISTICS BY STATE REQUIREMENTS IN RESIDENTIAL CARE}

V. Rome ${ }^{1}$, L. Harris-Kojetin, $\mathrm{PhD}^{2}$, P. Carder, $\mathrm{PhD}^{3}, 1$. National Center for Health Statistics, Hyattsville, Maryland, United States, 2. Chief, Long-Term Care Statistics Branch (LTCSB), Division of Health Care Statistics, National Center for Health Statistics (NCHS), Hyattsville, MD, USA , 3. Associate Professor, Institute on Aging, Portland State University, Portland, Oregon, USA

This study analyzed variation in the prevalence, levels, and skill-mix of licensed nurse staffing by state requirements for licensed nurses in residential care. RCC staffing data were obtained from the 2014 National Study of Long-Term Care Providers and a report of regulations published by Carder et al. in 2016. Descriptive statistics examined variation in prevalence, levels, and skill-mix of licensed nurses among 
RCCs in states with requirements for a licensed nurse to be on staff or available through employment and RCCs in states that had no such requirement. Staffing characteristics varied considerably across states. A statistically significantly higher $(\mathrm{p}<.05)$ prevalence of registered nurses $(68.87 \%)$ and a statistically significantly higher $(\mathrm{p}<.05)$ prevalence and level of licensed practical or vocational nurses $(56.85 \%$ and $17 \mathrm{~min}$ utes) were found among RCCs in states with licensed nurse requirements, compared to RCCs in states with no such requirements $(37.35 \%, 29.08 \%$, and 8 minutes, respectively).

\section{STAFFING AND SERVICE AVAILABILITY IN ASSISTED LIVING: THE IMPORTANCE OF NURSE DELEGATION POLICIES}

A.S. Beeber ${ }^{1}$, S. Zimmerman, $\mathrm{PhD}^{2}$, C. Madeline Mitchell, MURP 3 , D. Reed, $\mathrm{PhD}^{4}$, 1. School of Nursing, Chapel Hill, North Carolina, United States, 2. School of Social Work, University of North Carolina at Chapel Hill, Chapel Hill, NC USA. Cecil G. Sheps Center for Health Services Research, University of North Carolina at Chapel Hill, Chapel Hill, NC, USA, 3. Cecil G. Sheps Center for Health Services Research, University of North Carolina at Chapel Hill, Chapel Hill, NC, USA, 4. Cecil G. Sheps Center for Health Services Research, University of North Carolina at Chapel Hill, Chapel Hill, NC, USA

This study examined the relationships among assisted living (AL) staffing, the availability of 26 services, and state delegation regulations (whether nurses can delegate care to other staff), using data from $245 \mathrm{AL}$ settings from eight U.S. states (CA, FL, IL, KS, NC, NH, NJ, OR). We found significantly more services available in AL settings in delegation states than non-delegation states (19.7 vs 18.1), and more medication technicians handling prescribed and PRN (as needed) medications $(\mathrm{p}<.001)$. In two-way comparisons of nurse staffing categories (none, LPNs only, RNs only, LPNs and RNs), AL communities with no nurses offered the lowest number of services and those with RNs only offered a significantly lower number of services than those with LPNs only. This session will illustrate how AL staffing and service availability relate to statewide nurse delegation practices, and discuss the significance of this work to understanding the overall quality of care in AL.

\section{COMMUNITY AND ADMINISTRATOR CHARACTERISTICS ASSOCIATED WITH RCC ADMINISTRATOR TENURE}

S. Dys ${ }^{1}$, T. Tunalilar, $\mathrm{PhD}^{2}$, P. Carder, $\mathrm{PhD}^{3}$, 1. Portland State University Institute on Aging, Portland, Oregon, United States, 2. Research Assistant, Institute on Aging, Portland State University, Portland, OR, USA, 3. Associate Professor, Institute on Aging, Portland State University, Portland, OR, USA

Hiring and retaining competent professionals managing service delivery is a challenging issue for all sectors of health and long-term care, especially residential care communities (RCCs). Considering the association between administrative turnover and replacement costs, lower quality of care, and poor resident outcomes, developing successful intervention programs to increase retention necessitates a better understanding of the organizational and personal factors driving the turnover. To rectify the exclusive focus of extant research on nursing homes and direct care workers, we examine correlates of administrator tenure using data from the 2010 National Survey of Residential Care Facilities, a nationally representative sample of RCCs in the United States $(\mathrm{n}=2,252)$. We find that administrators who are older and those without higher degrees are more likely to have longer tenure. Administrators employed in RCCs that are non-chain, smaller, older, with higher occupancy, and with a dementia care unit are also more likely to have longer tenure.

\section{SESSION 2480 (SYMPOSIUM)}

\section{INNOVATIONS IN REMINISCENCE AND LIFE REVIEW INTERVENTIONS}

Chair: G.J. Westerhof, University of Twente, Enschede, Overijssel

Reminiscence and life review interventions have a long tradition in gerontology. They support people in recollecting, evaluating, and integrating personal memories of their lives and thereby strengthen identities, social relationships, and life purpose and meaning. They have been found to be effective in promoting mental health and well-being in later life. These five presentations seek new avenues to implement reminiscence and life review interventions in order to contribute to longer lives with purpose. They discuss the use of interventions in five different target groups that are at risk of a loss of purpose in later life: Taiwanese older adults, older African Americans, people with dementia, Vietnam Veterans, and people with terminal illness. Each intervention is tailored to the needs of the specific target groups: from a focus on sharing life stories, rethinking life stories, and capturing memories with technology, to sequencing and integrating life review with psychotherapeutic methods. The symposium shows how different research methods contribute to more insight in interventions: qualitative interviews address the meaning of the intervention from the perspective of older adults themselves, whereas randomized controlled trials are able to assess the intervention effects on a variety of psychosocial outcomes. The symposium brings American, Dutch, Israeli, and Taiwanese researchers together, who are members of the International Institute for Reminiscence and Life Review. Together, the presentations provide new insights how interventions can be tailored to the diversity of aging experiences.

\section{“SILVER LEGENDS” IN TAIWAN - AN APPLICATION FROM LIFE REVIEW TO PRODUCTIVE AGING}

T. Kuo, Chung Shan Medical University, Taichung City, Taichung, Taiwan (Republic of China)

Life review often led to better understanding of self and leading to life integration or self-actualization. The purpose of this research was to examine what characteristics existed when 15 older adults participated in a 10-session life review group, with the objective to share their life stories to different audiences upon the completion of the group. The 15 older adults were called "Silver Legends." Both the life review content and interviews after sharing in the communities were analyzed qualitatively by using content analysis. This results were 10 characteristics organized into three categories: charisma, preservation and contribution. The 10 characteristics were persistence, positive attitudes, interests, self-concept, 